\title{
Who Attains Status? \\ Similarities and Differences Across Social Contexts
}

Nicole M. Lawless DesJardins and Sanjay Srivastava

University of Oregon, Eugene, OR, USA

Albrecht C. P. Küfner and Mitja D. Back

University of Münster, Münster, Germany

NOTE: This is a preprint version of a published manuscript. The final published version is:

Lawless DesJardins, N., Srivastava, S., Küfner, A. C. P., \& Back, M. D. (2015). Who attains status? Similarities and differences across social contexts. Social Psychological and Personality Science, 6, 692-700. DOI: 10.1177/1948550615580171

\section{CORRESPONDING AUTHOR:}

Nicole M. Lawless DesJardins

Psychology Department

1227 University of Oregon

Eugene, OR 97403

nlawless@uoregon.edu 
STATUS ATTAINMENT ACROSS SOCIAL CONTEXTS

\section{DECLARATION OF CONFLICT OF INTEREST:}

The authors declared no potential conflicts of interests with respect to the authorship and/or publication of this article.

\section{FINANCIAL DISCLOSURE/FUNDING:}

The authors disclosed receipt of the following financial support for the research and/or authorship of this article: Grant BA 3731/6-1 of the German Research Foundation (DFG) to Mitja Back, Steffen Nestler, \& Boris Egloff. 


\title{
STATUS ATTAINMENT ACROSS SOCIAL CONTEXTS
}

\author{
Abstract \\ Informal groups form hierarchies and allocate social status in order to coordinate action \\ and make collective decisions. Although researchers have identified characteristics of people \\ who tend to get status, the extent to which these characteristics are context-dependent is unclear. \\ In two studies, participants from the United States $(N=157)$ and Germany $(N=95)$ engaged in \\ affiliative or competitive group interactions. We investigated whether the nature of the group's \\ task moderated the relationship between status attainment and personality. As in previous \\ research, we found that extraversion predicted status in both competitive and affiliative contexts. \\ In contrast, agreeableness was only associated with status in affiliative contexts. These findings \\ underscore the importance of examining the relationship between personality and social status in \\ context. \\ KEYWORDS: Status, Person Perception, Individual Differences, Interpersonal Processes, \\ Personality
}




\section{STATUS ATTAINMENT ACROSS SOCIAL CONTEXTS}

Who Attains Status? Similarities and Differences Across Social Contexts

Status-based hierarchies are formed through dynamic processes that aim to facilitate collective decisions and coordinate actions. Without a formally assigned leader, group members distribute status amongst themselves and grant more status to some people than to others. Researchers have identified numerous strategies and characteristics that contribute to status attainment (e.g, Anderson, John, Keltner \& Kring, 2001; Berger, Cohen \& Zelditch, 1972; Cheng, Tracy, Foulsham, Kingstone \& Henrich, 2013). But do these characteristics predict status across situations, or are they context-dependent?

In the current investigation, we examined whether the same personality traits predicted status in groups performing different tasks. We were particularly interested in determining the degree to which individual differences in agreeableness and extraversion would be associated with status in affiliative versus competitive contexts. Previous investigations of status attainment have tended to neglect the role of different contexts, even though status differentiation processes may vary across situations. Individuals with status are instrumental in directing their group in social and organizational settings, and understanding when certain individuals tend to attain status may inform future research aimed at increasing group efficacy in these settings.

\section{Who Attains Status?}

When people interact in groups without formally designated leaders, they spontaneously form informal hierarchies based on social status - how much respect, esteem or influence group members confer onto one another (Berger, Rosenholtz \& Zelditch, 1980; Magee \& Galinsky, 2008). The primary function of a hierarchy is to facilitate efficient performance toward a common goal (Magee \& Galinsky, 2008), and the person who attains status often becomes an informal leader who coordinates the group's actions. 


\section{STATUS ATTAINMENT ACROSS SOCIAL CONTEXTS}

Groups allocate status based, in substantial part, on who will help the group complete its task. When characteristics that contribute directly to the task are known and can be observed by group members, they are used to confer status and, thus, to select the leader (Berger et al., 1980). People with abilities specifically related to the group's task (e.g., math proficiency when solving math problems; Anderson \& Kilduff, 2009a), or who demonstrate broad competencies through general intelligence (Lord, De Vader \& Alliger, 1986), tend to attain status.

Personality traits might also contribute to status attainment because they subsume stable individual differences in how people act in social groups. In fact, extraversion - how outgoing, assertive or sociable someone is (Costa \& McCrae, 1995; John \& Srivastava, 1999) — consistently predicts status attainment (Anderson et al., 2001; Judge, Bono, Ilies \& Gerhardt, 2002). Individual differences in dominance, a facet of extraversion, are associated with being seen as a leader (Lord, et al., 1986) and having influence over the group's actions (Anderson \& Kilduff, 2009a).

Although researchers have focused on extraversion, other traits might also be important. Here we consider agreeableness. Status is usually assigned based on a group member's ability to positively contribute to the group, and agreeable people may promote group cohesion and cooperation. However, the results linking status to individual differences in agreeableness are less robust than those for extraversion. In previous studies, agreeableness has been only weakly correlated with status (Anderson, et al., 2001) and the related construct of leadership (Judge, et al., 2002). There are at least two potential explanations for this small and unreliable association. First, individual differences in agreeableness may not affect status. Second, the relationship between agreeableness and status could be variable and context-dependent. That is, 


\section{STATUS ATTAINMENT ACROSS SOCIAL CONTEXTS}

agreeableness may be positively associated with status in some situations, but negatively or not associated in others, resulting in a small net effect when context is not accounted for.

\section{Personality, Status Attainment, and Context}

How might the relationship between personality and status attainment vary across contexts? We propose that the answer lies in a circumplex model of interpersonal behavior, defined by dominance on the vertical axis and warmth on the horizontal axis (Leary, 1957; Wiggins, 1991). Dominance is closely related to Big Five extraversion and warmth to agreeableness (DeYoung, Weisberg, Quilty \& Peterson, 2013), and these interpersonal dimensions describe individuals' personalities as well as interpersonal relationships (Fiske \& Haslam, 2005; McCrae \& Costa, 1989; Wiggins, 1991).

Studies of complementarity - how one person's behavior affects another person's behavior - indicate that dominant behavior tends to invite submissive behavior and vice versa, whereas warm behavior invites similarly warm responses, and cold behavior invites cold responses (Horowitz et al., 2006; Markey, Funder \& Ozer, 2003; Tiedens \& Fragale, 2003). Based on this model, an extraverted individual would be expected to attain status across many contexts. Extraverts may attain status because they are assertive and make themselves more visible (e.g., by speaking up), which allows them to be socially engaged with their group members (Anderson \& Kilduff, 2009b; Keltner, Van Kleef, Chen \& Kraus, 2008) without being overtly controlling or aggressive. Because people who are low in extraversion are submissive and withdrawn, they are not expected to attain status in any context.

On the other hand, agreeableness may only contribute to status attainment when the group will benefit from warmth. When the group's task requires trust and cooperation, an agreeable leader may both demonstrate the qualities necessary to complete the task and draw 


\section{STATUS ATTAINMENT ACROSS SOCIAL CONTEXTS}

those qualities out of other group members. In contrast, if the task calls for group members to compete with each other, generating closeness may not provide a functional benefit to the group as a whole. In principle, agreeableness could even be detrimental to status if it inhibits completion of the competitive task. We therefore expected either no association or perhaps a negative association between agreeableness and status attainment in competitive situations.

\section{Current Studies}

We examined the emergence of informal status hierarchies in competitive or affiliative situations, and tested whether these situational differences moderated the relationship between personality traits and status attainment in two countries with two different measures of status.

\section{Study 1}

This study tested the extent to which extraversion and agreeableness predicted status in a loosely structured interaction. Participants completed either a leaderless group discussion (LGD; adapted from John \& Robins, 1994 and Staw \& Barsade, 1993) in which they competed for limited resources, or a mutual self-disclosure task (adapted from Aron, Melinat, Aron, Vallone, \& Bator, 1997). After the task, we obtained round-robin ratings to measure each individual's status in the group.

\section{Method}

Participants. 181 undergraduates $\left(71 \%\right.$ female, $M_{a g e}=18.4, S D_{a g e}=7.95 ; 93 \%$ White $)$ from a university in the Pacific Northwest participated in exchange for partial course credit. The University's Institutional Review Board approved all procedures. Because we used the Social Relations Model (SRM; see below) to obtain the dependent measure, only groups with four or more participants were included in our analyses. Seven groups had three or fewer members, and one group ran out of its scheduled time before participants could complete the status item. 22 


\section{STATUS ATTAINMENT ACROSS SOCIAL CONTEXTS}

participants in these groups, which were equally distributed across both conditions, were excluded from analysis. This exclusion resulted in a final sample size of $N=157$ participants (73\% female; $M_{\text {age }}=19, S D_{\text {age }}=1.80 ; 92 \%$ White $)$.

Participants who completed the LGD ( $n=103, k=22$ groups) were recruited during the fall and winter terms of the academic year, whereas participants who completed the selfdisclosure task ( $n=54, k=13$ groups) were recruited during the spring term of the same academic year. Each participant completed only one of the tasks. For practical reasons, we determined sample size by deciding on a fixed period of time in advance (coinciding with the academic term) and then ran as many subjects as we could during that time. No analyses were conducted until data collection was completed.

Procedure and measures. Participants completed the Big Five Inventory (BFI; John \& Srivastava, 1999) online approximately one week before coming into the lab. Participants answered each of 44 items on a scale from 1 (disagree strongly) to 5 (agree strongly); item responses were averaged to compute scale scores. Differences between the LGD and selfdisclosure groups on this pre-test measure of extraversion $\left(M_{\text {Self-Disclosure }}-M_{L G D}=-0.05,95 \%\right.$ CI [$\left.0.29,0.19]^{1}\right)$ and agreeableness $\left(M_{\text {Self-Disclosure }}-M_{L G D}=-0.16,95 \%\right.$ CI $\left.[-0.37,0.05]\right)$ were very near zero, and the confidence intervals indicate that the difference was negligible between these two samples. Descriptive statistics and alpha coefficients can be found in Table 1.

Participants arrived to the lab in mixed-sex groups of four or five participants.

Participants were unacquainted with one another prior to the lab session. All of the group interactions lasted approximately 20 minutes.

Participants in the LGD groups were asked to take on the role of a regional representative of the university alumni association; as a group, the representatives formed an awards committee 


\section{STATUS ATTAINMENT ACROSS SOCIAL CONTEXTS}

that was charged with distributing prize money to the nominees. Each participant received information about a nominee from the association chapter that they represented. Participants were asked to advocate for their nominee, and, as a group, select a first prize winner (who would receive the largest award), and determine how to divide the remaining prize money amongst the rest of the nominees. Participants were instructed to give different amounts of money to each nominee. As such, participants competed over the allocation of limited resources, and were tasked with working both for the interest of their chapter's nominee and the broader interest of the committee.

Participants in the self-disclosure groups were asked to get to know one another. Following Aron et al. (1997), participants took turns drawing cards from an envelope. Questions were printed on each card, and participants were instructed to take turns reading the questions aloud. After a question was read, each participant in the group answered the question; questions became more intimate as the game proceeded. The participants' goal in this group task was to simply get to know one another by sharing information about themselves.

After the interaction, participants rated themselves and each of their group members. Participants were instructed to provide different ratings for each group member (i.e., they were not supposed to give ties in their ratings). To obtain our measure of status, participants indicated whether each group member "had high status (influence, power) in the group" on a 0 (disagree strongly) to 10 (agree strongly) scale $(M=6.27, S D=1.66)$. Because of the round-robin design

of the study, in which each participant rated a different set of others, we used the social relations model (SRM; Kenny, 1994) to obtain unbiased ratings of each participant's status in the group. Individual differences in how certain perceivers tend to view others can bias ratings when all of the perceptions of a single individual are averaged together (e.g., Cronbach, 1955). SRM 


\section{STATUS ATTAINMENT ACROSS SOCIAL CONTEXTS}

removes this bias from the ratings of each individual. SRM also removes the group mean from each rating (i.e., the ratings are group mean centered), which eliminates group dependencies and makes the data appropriate for single-level regression analyses. SRM analyses were conducted in the TripleR package in R (Schönbrodt, Back \& Schmukle, 2012), and the target effects (i.e., the average rating for each participant, controlling for group and perceiver differences) for the status item obtained from these analyses was our dependent measure.

\section{Results}

SRM decomposition. To determine whether group members agreed about each other's status, we first examined the amount of variance in status ratings explained by targets and perceivers relative to the total variance. The proportion of variance explained by targets provides an estimate of the extent to which group members agree about particular others (i.e., it is a measure of consensus), whereas the proportion of variance explained by perceivers provides an estimate of the extent to which different perceivers use different baseline levels of status ratings across targets (i.e., it is a measure of the influence of individual differences on the tendency to see others as leaders). In this sample, $34 \%$ of the variance in status ratings was attributable to targets, whereas $20 \%$ was attributable to perceivers. The target estimate is similar to what has been reported elsewhere (e.g., Anderson \& Kilduff, 2009a; Anderson et al., 2006; Srivastava \& Anderson, 2011). For comparison, Srivastava and Anderson (2011) reported in a similar study of unstructured small group interactions that $28 \%$ of the variance in status ratings was attributable to targets, whereas $35 \%$ was attributable to perceivers. This high proportion of target variance indicates substantial agreement amongst group members regarding who attained status.

Main analyses. To determine the extent to which people with different personalities attained status in different situations, we predicted the standardized target effect of the status 


\section{STATUS ATTAINMENT ACROSS SOCIAL CONTEXTS}

item from the standardized personality scale score, a contrast-coded condition variable $(1=$ selfdisclosure; -1 = LGD), and the interaction between the two. Full results are presented in Table 2 . As anticipated, we found a positive effect of extraversion, $b=.25$, with a $95 \%$ CI of $[0.08$, $0.42]^{2}$, and this effect was not moderated by condition $(b=-.01, \mathrm{CI}[-0.18,0.16])$. In contrast, we did not find evidence of a clear main effect of agreeableness $(b=.10$, CI $[-0.06,0.26])$, but we did find that condition moderated the effect of agreeableness on status attainment $(b=.19$, CI $[0.03,0.35]) .^{3}$ As can be seen in Figure 1 , agreeableness is clearly positively associated with status in the self-disclosure groups $(b=.29, \mathrm{CI}[.09, .48])$, but the association is negligible in the LGD groups $(b=-.09$, CI $[-.31, .14]){ }^{4}$

\section{Summary}

As in previous research, extraversion predicted status in both competitive and affiliative contexts. In contrast, we found preliminary evidence that agreeableness does matter for status attainment, but only in affiliative contexts. However, in this study, participants were not explicitly told to compete or affiliate with one another. In addition, we ran the conditions sequentially rather than randomly assigning participants. These limitations were addressed in Study 2 .

\section{Study 2}

This study estimated the same theoretical effects as Study 1 but with different tasks and a different measure of status (a “conceptual replication”). In Study 2 we improved the experimental manipulation by more closely matching the tasks across conditions and explicitly instructing participants to compete or cooperate with one another. We also had every participant complete two tasks (either both cooperative or both competitive) to obtain a more reliable estimate of the relationship between personality and status attainment. 


\section{STATUS ATTAINMENT ACROSS SOCIAL CONTEXTS}

\section{Method}

Participants. 104 university students $\left(71 \%\right.$ female; $\left.M_{\text {age }}=23, S D_{\text {age }}=3.92\right)$ from a university in Germany participated in exchange for $30 €$ or course credit. The University's Institutional Review Board approved all procedures. Nine participants did not provide personality data and were excluded from all analyses including personality $(N=95,72 \%$ female; $M_{\text {age }}=23, S D_{\text {age }}=3.92$ ). The experiment was completed as part of a larger longitudinal study. For practical reasons, sample size was determined by deciding on a fixed period of time in advance and then running as many subjects as possible within that time. No analyses were run until the data collection was completed.

Procedure and materials. Participants completed the 15-item GSOEP Big Five Inventory (BFI-S; Hahn, Gottschling, \& Spinath, 2012) with two additional items for agreeableness (see Rammstedt \& John, 2007) online approximately one week before coming into the lab. Participants indicated the extent to which each item described them using a 1 (not at all true) to 7 (totally true) scale. Descriptive statistics and alpha coefficients can be found in Table $1^{5}$

Participants arrived to the lab in mixed-sex groups of four to six participants and had briefly met one another prior to this lab session. Each group was randomly assigned to complete either two competitive ( $n=50, k=9$ groups) or two cooperative ( $n=45, k=8$ groups) tasks. The tasks were completed in a fixed order, regardless of condition, and each task lasted up to 20 minutes. First, participants engaged in a modified Lost on the Moon (LOM) task (adapted from Robins \& Beer, 2001), in which they were told that they had just crash landed on the moon and needed to prioritize a limited set of items to help them get back to the mother ship. Cooperative groups were instructed to develop a list of items that would optimize the group's ability to get 


\section{STATUS ATTAINMENT ACROSS SOCIAL CONTEXTS}

back to the ship. Competitive groups were instructed to trade a fixed number of items amongst themselves in order to optimize their own individual ability to get back to the ship. After completing this task, participants indicated how well they could imagine each of their group members as a leader, using a scale from 1 (does not apply at all) to 6 (applies perfectly) $(M=$ $3.87, S D=1.20)$.

After the LOM task, groups discussed an adjusted variant of the ticking time bomb (TTB) scenario, a common thought experiment in ethics debates about the justification of torture (Association for the Prevention of Torture, 2007). Participants were told that a terrorist was in police custody and would only divulge information about an upcoming attack if tortured. Cooperative groups were instructed to reach a consensus about whether or not the terrorist should be tortured. Competitive group members were instructed to convince one another about their own individual positions. After completing the TTB scenario, participants again rated each of their group members using the same leadership item $(M=3.86, S D=1.23)$.

As in Study 1, we obtained unbiased estimates of leadership by conducting SRM analyses using the TripleR package (Schönbrodt et al., 2012) in R. The dependent variables were the target effects of leadership from both tasks obtained from these analyses.

\section{Results}

SRM decomposition. To determine whether group members agreed about each other's status, we again examined the amount of variance in leadership ratings explained by targets and perceivers relative to the total variance. For leadership ratings following the LOM task, $22 \%$ of the variance was attributable to targets, whereas $20 \%$ was attributable to perceivers. Following the TTB scenario, $22 \%$ of the variance was attributable to targets and $19 \%$ was attributable to 


\section{STATUS ATTAINMENT ACROSS SOCIAL CONTEXTS}

perceivers. As in Study 1, the relatively high proportion of target variance indicates substantial agreement amongst group members regarding who attained status in the group.

Main analyses. Because the same participants completed both tasks, we analyzed the data with a general linear model specifying task (LOM or TTB) and personality as betweensubjects variables and condition (cooperate or compete) as a within-subjects factor (Judd, Kenny \& McClelland, 1989). We did not anticipate that task would moderate any of the effects of personality or condition on status attainment. In order to test for differences between the LOM and TTB tasks, we first standardized both leadership ratings based on their pooled mean and pooled standard deviation and then tested for interactions of task with personality, condition, and both (the 3-way interaction). As anticipated, we did not find evidence for any interactions with task. Results of this analysis can be seen in Table 3.

Because there were no interactions with task, we collapsed across the LOM and TTB tasks for the main analyses. We then examined effects of the standardized personality score, the contrast-coded condition variable, and the interaction between the two. As in Study 1, extraversion had a substantial, positive effect on status, $b=.36$, CI $[0.16,0.55]$, and this effect was not moderated by condition, $b=.05$, CI $[-0.15,0.25]$. We did not find evidence of a main effect of agreeableness, $b=.04$, CI [-0.16, 0.25], but we did find evidence that condition moderated the effect of agreeableness on status attainment $(b=.21$, CI $[0.004,0.41])$. Simple effects analyses indicated that the effect of agreeableness on status attainment in the cooperative condition was positive, $b=.25, \mathrm{CI}[-.05, .55]$, but this effect was negative, $b=-.17, \mathrm{CI}[-.45, .12]$ in the competitive condition. This pattern of effects can be seen in Figure 2.

\section{Mini Meta-Analysis}




\section{STATUS ATTAINMENT ACROSS SOCIAL CONTEXTS}

The results of Study 1 were replicated in Study 2: extraversion predicted status attainment in both competitive and affiliative conditions, whereas the relationship between agreeableness and status attainment was moderated by condition. To summarize these effects, we conducted a meta-analysis on the effects of extraversion and agreeableness and their interactions with condition. To do so, we used a random effects model to combine the pairwise correlations between status and personality trait across the competitive and affiliative conditions in each study with Comprehensive Meta-Analysis Software (Biostat, 2014). For extraversion, the average correlation with status in the competitive condition was $r=.26$, CI $[.11, .41]$; the correlation in the affiliative condition was $r=.34$, CI $[.15, .51]$; and the overall correlation was $r$ $=.29, \mathrm{CI}[.17, .40]$. Together, these estimates and intervals indicate a consistent, moderately sized, positive relationship between extraversion and status across both types of situations. For agreeableness, the average correlation with status in the competitive condition was $r=-.11$, CI [$.26, .06]$; the correlation in the affiliative condition was $r=.32$, CI $[.13, .49]$; and the overall correlation was $r=.07$, CI [-.06, .19]. Unlike extraversion, the relationship between agreeableness and status varies based on the context: although the overall effect of agreeableness is near zero, there is a moderately sized positive effect in affiliative contexts, and a small negative effect in competitive contexts. See Figure 3 for the forest plots of the confidence intervals associated with these estimates.

\section{Discussion}

We examined whether the same personality traits were associated with status in different contexts. Extraversion was positively associated with status attainment across situations, consistent with previous research. Agreeableness was positively associated with status in affiliative contexts, but either had no or a small, negative effect in competitive contexts. 


\section{STATUS ATTAINMENT ACROSS SOCIAL CONTEXTS}

Importantly, these results replicated across samples in two countries and with two measures of status.

These findings underscore the importance of examining personality and status attainment in context. Previous investigations revealed correlations between agreeableness and status very near zero. For instance, in their meta-analysis, Judge et al. (2002) reported an average correlation of just $r=.06$ (p. 771, Table 2), and Anderson et al. (2001) reported an average of $r=.12$ for men and $r=.08$ for women (p. 126, Table 5) across three studies. However, neither paper distinguished between the different goals and contexts of the groups in question. Our results are consistent with these effects: across conditions, the average correlation between agreeableness and status was $r=.07$.

The relationship between agreeableness and status attainment was only revealed when warmth may have helped the group. When the group task required self-disclosure or cooperation, the size of the effect of agreeableness approached that of extraversion. Our interpretation is that personality contributed to task-relevant behavior in these social groups: individuals with higher levels of task-relevant traits were given status because they helped the group pursue its collective goals.

\section{Limitations \& Future Directions}

Despite the consistency of our main findings, this study has limitations. First, it is unclear how these results apply to longer-term, higher-stakes, or formal groups. For instance, Bendersky \& Shah (2013) found that the initially positive relationship between extraversion and status changed over time in groups that worked together over the course of 10 weeks. Given the very brief interlude between the two tasks in Study 2, we did not expect to find differences in the relationship between personality and leadership across the two tasks. However, examining the 


\section{STATUS ATTAINMENT ACROSS SOCIAL CONTEXTS}

contribution of different personality traits to status in different contexts both when the group first forms and over time is an important area for future research. In addition, Anderson et al. (2008) did not find a relationship between agreeableness and influence in an organization that valued cooperation. Although there are a number of differences between this and the current study (e.g., formal vs. informal groups; long-term vs. short-term acquaintanceships among members), it may be that agreeableness contributes to social status only during specific tasks that require agreeable behavior. When agreeable behaviors are broadly valued but not necessary to complete a particular task, agreeableness may be less likely to contribute to status.

Second, neither study included a manipulation check to determine whether participants perceived the tasks as competitive or cooperative. This limits our ability to make claims about the extent to which participants espoused the task goals that were given to them. However, we used tasks that have been previously validated to engender competition and affiliation (Study 1) and that explicitly instructed participants to either compete or cooperate with one another (Study 2), which increases our confidence that our findings were due to the differences between the task assignments and not spurious.

Finally, future research should examine whether agreeable leaders generate more cooperative groups. Interpersonal circumplex models predict that agreeable leaders will invite warm behaviors from their subordinates. Although complementarity has been well-documented elsewhere (Horowitz et al., 2006; Markey, Funder \& Ozer, 2003; Tiedens \& Fragale, 2003), and the finding that agreeableness predicted status in affiliative contexts suggests that complementarity played a role in status attainment, we did not directly test this assumption, nor could we test whether these groups became warmer or closer over time.

\section{Conclusion}




\section{STATUS ATTAINMENT ACROSS SOCIAL CONTEXTS}

People tend to attain social status in informal groups when they can help the group reach its goal. Because groups' goals vary, different interpersonal characteristics may contribute to status attainment in different contexts. Although extraversion consistently predicted status attainment, we found that the relationship between agreeableness and status was moderated by context. Agreeable individuals attained status when warmth may have helped the group achieve its affiliative goals, but not when group members competed with one another.

\section{Notes}

1. CIs around the difference between means were computed without assuming equal variances in ESCI (Cumming, 2011).

2. Following the recommendation of Cumming (2012), we report only effect sizes and confidence intervals. The $95 \%$ CIs indicate that, were the study to be replicated $n$ times, the true value of the parameter would fall within the range provided by the CI $95 \%$ of the time.

3. Three participants ( 1 in the LGD condition; 2 in the self-disclosure condition) scored more than 2.9 standard deviations below the mean on agreeableness. When removed from analysis, the estimate of the interaction decreased slightly and the 95\% CI included zero $(b=.13, \mathrm{CI}[-.06$, $.31])$. The leverage statistics for these participants were within an acceptable range $(<.20$; Judd \& McClelland, 1989), and examination of the residuals for the entire sample indicated that the assumption of normality was not violated. Thus, we included these individuals in all analyses. 4. Please see the online supplemental material for exploratory analyses examining the effects of conscientiousness, neuroticism and openness.

5. The GSOEP Big Five Inventory (and other similar short measures of the Big Five) was designed to assess complementary aspects of broad Big Five domains rather than maximize internal consistency via redundant content, so alpha coefficients underestimate the true reliability 


\section{STATUS ATTAINMENT ACROSS SOCIAL CONTEXTS}

of these scales and are expected to be lower than the reliabilities of longer-form questionnaires (Schmitt, 1996). 


\section{STATUS ATTAINMENT ACROSS SOCIAL CONTEXTS}

\section{References}

Anderson, C., John, O. P., Keltner, D., \& Kring, A. M. (2001). Who attains social status? Effects of personality and physical attractiveness in social groups. Journal of Personality and Social Psychology, 81, 116-132. doi: 10.1037//0022-3514.81.1.116

Anderson, C., Srivastava, S., Beer, J. S., Spataro, S. E., \& Chatman, J. A. (2006). Knowing your place: Self-perceptions of status in face-to-face groups. Journal of Personality and Social Psychology, 91, 1094-1110. doi:10.1037/0022-3514.91.6.1094

Anderson, C. \& Kilduff, G. J. (2009a). Why do dominant personalities attain influence in faceto-face groups? The competence-signaling effects of trait dominance. Journal of Personality and Social Psychology, 96, 491-503. doi:10.1037/a0014201

Anderson, C. \& Kilduff, G.J. (2009b). The pursuit of status in social groups. Current Directions in Psychological Science, 18, 295 - 298. doi: 10.1111/j.1467-8721.2003.01655.x

Anderson, C., Spataro, S.E. \& Flynn, F.J. (2008). Personality and organizational culture as determinants of influence. Journal of Applied Psychology, 93, 702-710. doi: 10.1037/0021-9010.93.3.702

Aron, A., Melinat, E., Aron, E. N., Vallone, R. D., \& Bator, R. J. (1997). The experimental generation of interpersonal closeness: A procedure and some preliminary $\mathrm{f}$ indings. Personality and Social Psychology Bulletin, 23, 363-377.

Association for the Prevention of Torture. (2007). Diffusing the ticking bomb scenario: Why we must say no to torture, always. Retrieved from http://www.apt.ch/content/files_res/tickingbombscenario.pdf.

Bendersky, C. \& Shah, N.P. (2013). The downfall of extraverts and rise of neurotics: The 


\section{STATUS ATTAINMENT ACROSS SOCIAL CONTEXTS}

dynamic process of status allocation in task groups. Academy of Management Jounral, $56,387-406$.

Berger, J., Cohen, B. P., \& Zelditch Jr, M. (1972). Status characteristics and social interaction. American Sociological Review, 241-255.

Berger, J., Rosenholtz, S., \& Zelditch, M. (1980). Status Organizing Processes. Annual Review of Sociology, 6, 479-508.

Biostat. (2014). Comprehensive Meta-Analysis (Version 2) [Software]. Available from www.meta-analysis.com

Cheng, J. T., Tracy, J. L., Foulsham, T., Kingstone, A., \& Henrich, J. (2013). Two ways to the top: Evidence that dominance and prestige are distinct yet viable avenues to social rank and influence. Journal of Personality and Social Psychology, 104, 103-125. doi: $10.1037 / \mathrm{a} 0030398$

Cronbach, L. (1955). Processes affecting scores on "understanding of others" and " assumed similarity.” Psychological Bulletin, 52, 177-193.

Cumming, G. (2001-2011). ESCI, Exploratory Software for Confidence Intervals. Computer software, available from:http://www.latrobe.edu.au/psy/research/projects/esci

Costa, P. T., \& McCrae, R. R. (1995). Domains and facets: Hierarchical personality assessment using the Revised NEO Personality Inventory. Journal of Personality Assessment, 64, 2150.

DeYoung, C. G., Weisberg, Y. J., Quilty, L. C., \& Peterson, J. B. (2013). Unifying the aspects of the Big Five, the interpersonal circumplex, and trait affiliation. Journal of Personality, 81, 465-475.

Fiske, A. P., \& Haslam, N. (2005). The Four Basic Social Bonds: Structures for Coordinating 


\section{STATUS ATTAINMENT ACROSS SOCIAL CONTEXTS}

Interaction. In M. W. Baldwin (Ed.), Interpersonal Cognition, 267-298. New York: Guilford Press.

Hahn, E., Gottschling, J., \& Spinath, F.M. (2012). Short measurements of personality - Validity and reliability of the GSOEP Big Five Inventory (BFI-S). Journal of Research in Personality, 46, 355-359.http://dx.doi.org/10.1016/j.jrp.2012.03.008

Horowitz, L. M., Wilson, K. R., Turan, B., Zolotsev, P., Constantino, M. J., \& Henderson, L. (2006). How interpersonal motives clarify the meaning of interpersonal behavior: A revised circumplex model. Personality and Social Psychology Review, 10, 67-86. doi:10.1207/s15327957pspr1001_4

John, O.P. \& Robins, R.W. (1994). Accuracy and bias in self-perception: Individual differences in self-enhancement and the role of narcissism. Journal of Personality and Social Psychology, 66, 206-219.

John, O. P. \& Srivastava, S. (1999). The Big Five trait taxonomy: History, measurement, and theoretical perspectives. In L. A. Pervin \& O. P. John (Eds.), Handbook of personality: Theory and research (2nd ed., pp. 102-138). New York: Guilford.

Judd, C.M. \& McClelland, G.H. (1989). Data analysis: A model comparison approach. San Diego: Harcourt Brace Jovanovich.

Judd, C. M., Kenny, D. A., \& McClelland, G. H. (2001). Estimating and testing mediation and moderation in within-subject designs. Psychological Methods, 6, 115-134. doi: 10.1037/1082-989X.6.2.115

Judge, T.A., Bono, J.E., Ilies, R. \& Gerhardt, M.W. (2002). Personality and leadership: A qualitative and quantitative review. Journal of Applied Psychology, 87, 765-780. doi: $10.1037 / / 0021-9010.87 .4 .765$ 


\section{STATUS ATTAINMENT ACROSS SOCIAL CONTEXTS}

Keltner, D., Van Kleef, G. A., Chen, S., \& Kraus, M. (2008). A reciprocal influence model of social power: Emerging principles and lines of inquiry. Advances in Experimental Social Psychology, 40, 151-192.

Kenny, D. A. (1994). Interpersonal perception: A social relations analysis. Guilford Press.

Leary, T. (1957). Interpersonal diagnosis of personality; a functional theory and methodology for personality evaluation. Oxford, England: Ronald Press.

Lord, R. G., De Vader, C. L., \& Alliger, G. M. (1986). A meta-analysis of the relation between personality traits and leadership perceptions: An application of validity generalization procedures. Journal of Applied Psychology, 71, 402-410. doi: 10.1037/0021-

9010.71 .3 .402

Magee, J. C., \& Galinsky, A. D. (2008). Social hierarchy: The self-reinforcing nature of power and status. Academy of Management Annals, 2, 351-398.

doi:10.1080/19416520802211628

Markey, P. M., Funder, D. C., \& Ozer, D. J. (2003). Complementarity of interpersonal behaviors in dyadic interactions. Personality and Social Psychology Bulletin, 29, 1082-1090. doi:10.1177/0146167203253474

McCrae, R. R., \& Costa, P. T. (1989). The structure of interpersonal traits: Wiggins's circumplex and the five-factor model. Journal of Personality and Social Psychology, 56, 586-595.

Rammstedt, B.\& John, O. P. (2007). Measuring personality in one minute or less: A 10-item short version of the Big Five Inventory in English and German. Journal of Research in Personality, 41, 203-212. doi:10.1016/j.jrp.2006.02.001

Robins, R. W. \& Beer, J. S. (2001). Positive illusions about the self: Short-term benefits and long-term costs. Journal of Personality and Social Psychology, 80, 340-352. 


\section{STATUS ATTAINMENT ACROSS SOCIAL CONTEXTS}

Schmitt, N. (1996). Uses and abuses of coefficient alpha. Psychological Assessment, 8, 350-353.

Schönbrodt, F. D., Back, M. D., \& Schmukle, S. C. (2012). TripleR: An R package for social relations analyses based on round-robin designs. Behavior Research Methods, 44, 455470. doi:10.3758/s13428-011-0150-4

Srivastava, S. \& Anderson, C. (2011). Accurate when it counts: Perceiving power and status in social groups. In J. L. Smith, W. Ickes, J. Hall, S. D. Hodges, \& W. Gardner ( Eds.), Managing interpersonal sensitivity: Knowing when-and when not-to understand others (pp. 41-58). Hauppage, NY: Nova Science Publishers.

Staw, B.M. \& Barsade, S.G. (1993). Affect and managerial performance: A test of the sadderbut-wiser vs. happier-and-smarter hypotheses. Administrative Science Quarterly, 38, 304331.

Tiedens, L. Z., \& Fragale, A. R. (2003). Power moves: Complementarity in dominant and submissive nonverbal behavior. Journal of Personality and Social Psychology, 84, 558568. doi:10.1037/0022-3514.84.3.558

Wiggins, J. S. (1991). Agency and communion as conceptual coordinates for the understanding and measurement of interpersonal behavior. In D. Cicchetti \& W.M. Grove (Eds.), Thinking clearly about psychology: Essays in honor of Paul E. Meehl, Vol. 2: Personality and psychopathology, 89-113, Minneapolis, MN: University of Minnesota Press. 


\section{STATUS ATTAINMENT ACROSS SOCIAL CONTEXTS}

\section{Tables:}

Table 1.

Pre-Interaction Big Five Inventory Descriptive Statistics

\begin{tabular}{|c|c|c|c|c|c|c|c|}
\hline \multirow[b]{2}{*}{ Trait } & \multirow[b]{2}{*}{ Condition } & \multicolumn{3}{|c|}{ Study 1} & \multicolumn{3}{|c|}{ Study 2} \\
\hline & & $M$ & $S D$ & $\alpha$ & $M$ & $S D$ & $\alpha$ \\
\hline \multirow[t]{3}{*}{ Extraversion } & Compete & 3.52 & 0.76 & .87 & 4.75 & 1.18 & .80 \\
\hline & Affiliate & 3.47 & 0.70 & .82 & 5.08 & 1.26 & .84 \\
\hline & Total & 3.50 & 0.74 & .85 & 4.91 & 1.23 & .82 \\
\hline \multirow[t]{3}{*}{ Agreeableness } & Compete & 4.01 & 0.56 & .76 & 5.07 & 0.93 & .69 \\
\hline & Affiliate & 3.85 & 0.66 & .81 & 4.96 & 0.90 & .57 \\
\hline & Total & 3.95 & 0.60 & .78 & 5.02 & 0.91 & .63 \\
\hline
\end{tabular}

Note: Self-reports of personality in Study 1 were made on a 1 (disagree strongly) to 5 (agree strongly) scale; self-reports in Study 2 were made on a 1 (not at all true) to 7 (totally true) scale. Sample sizes by cell were as follows: Study 1 , Compete $n=103, k=22$; Affiliate $n=54, k=13$; Study 2, Compete $n=50, k=9$, Affiliate $n=45, k=8$. 
STATUS ATTAINMENT ACROSS SOCIAL CONTEXTS

Table 2.

Effects of extraversion, agreeableness and condition on status (Study 1 results)

\begin{tabular}{llcccc} 
& & $\boldsymbol{b}$ & $\boldsymbol{S E}$ & \multicolumn{2}{c}{$\mathbf{9 5 \%}$ CI for b } \\
\hline Extraversion & Extraversion & 0.25 & 0.09 & 0.08 & 0.42 \\
& Condition & 0.01 & 0.08 & -0.15 & 0.17 \\
& E X Condition & -0.01 & 0.09 & -0.18 & 0.16 \\
\hline Agreeableness & Agreeableness & 0.10 & 0.08 & -0.06 & 0.26 \\
& Condition & 0.02 & 0.08 & -0.14 & 0.19 \\
& A X Condition & 0.19 & 0.08 & 0.03 & 0.35 \\
\hline
\end{tabular}

Note: Personality traits and status are standardized. Condition is coded as $-1=\mathrm{LGD}$ and $1=$ self-disclosure. 
STATUS ATTAINMENT ACROSS SOCIAL CONTEXTS

Table 3.

Effects of extraversion, agreeableness, condition and task on leadership (Study 2 results)

\begin{tabular}{llcccc} 
& & $\boldsymbol{b}$ & $\boldsymbol{S E}$ & \multicolumn{2}{c}{$\mathbf{9 5 \%}$ CI for $\boldsymbol{b}$} \\
\hline Extraversion & Extraversion & 0.36 & 0.10 & 0.16 & 0.55 \\
& Condition & -0.05 & 0.10 & -0.25 & 0.15 \\
& E X Condition & 0.05 & 0.10 & -0.15 & 0.25 \\
& Task & -0.03 & 0.05 & -0.13 & 0.08 \\
& E X Task & -0.04 & 0.05 & -0.15 & 0.06 \\
& Condition X Task & 0.00 & 0.05 & -0.10 & 0.11 \\
& E X Condition X Task & 0.08 & 0.05 & -0.03 & 0.18 \\
\hline Agreeableness & Agreeableness & 0.04 & 0.10 & -0.16 & 0.25 \\
& Condition & 0.00 & 0.10 & -0.20 & 0.21 \\
& A X Condition & 0.21 & 0.10 & 0.00 & 0.41 \\
& Task & -0.01 & 0.05 & -0.12 & 0.09 \\
& A X Task & 0.06 & 0.05 & -0.05 & 0.17 \\
& Condition X Task & 0.00 & 0.05 & -0.10 & 0.11 \\
& A X Condition X Task & 0.05 & 0.05 & -0.05 & 0.16 \\
\hline
\end{tabular}

Note: Personality traits are standardized. For analyses without task effects, leadership is the standardized of the average of the two leadership ratings. For analyses that include task effects, leadership is the difference between the two leadership ratings standardized based on the pooled mean and standard deviation. Condition is coded as $-1=$ compete and $1=$ cooperate. 
STATUS ATTAINMENT ACROSS SOCIAL CONTEXTS

\section{Figure captions:}

Fig. 1.

Effect of agreeableness on status attainment moderated by condition (Study 1)

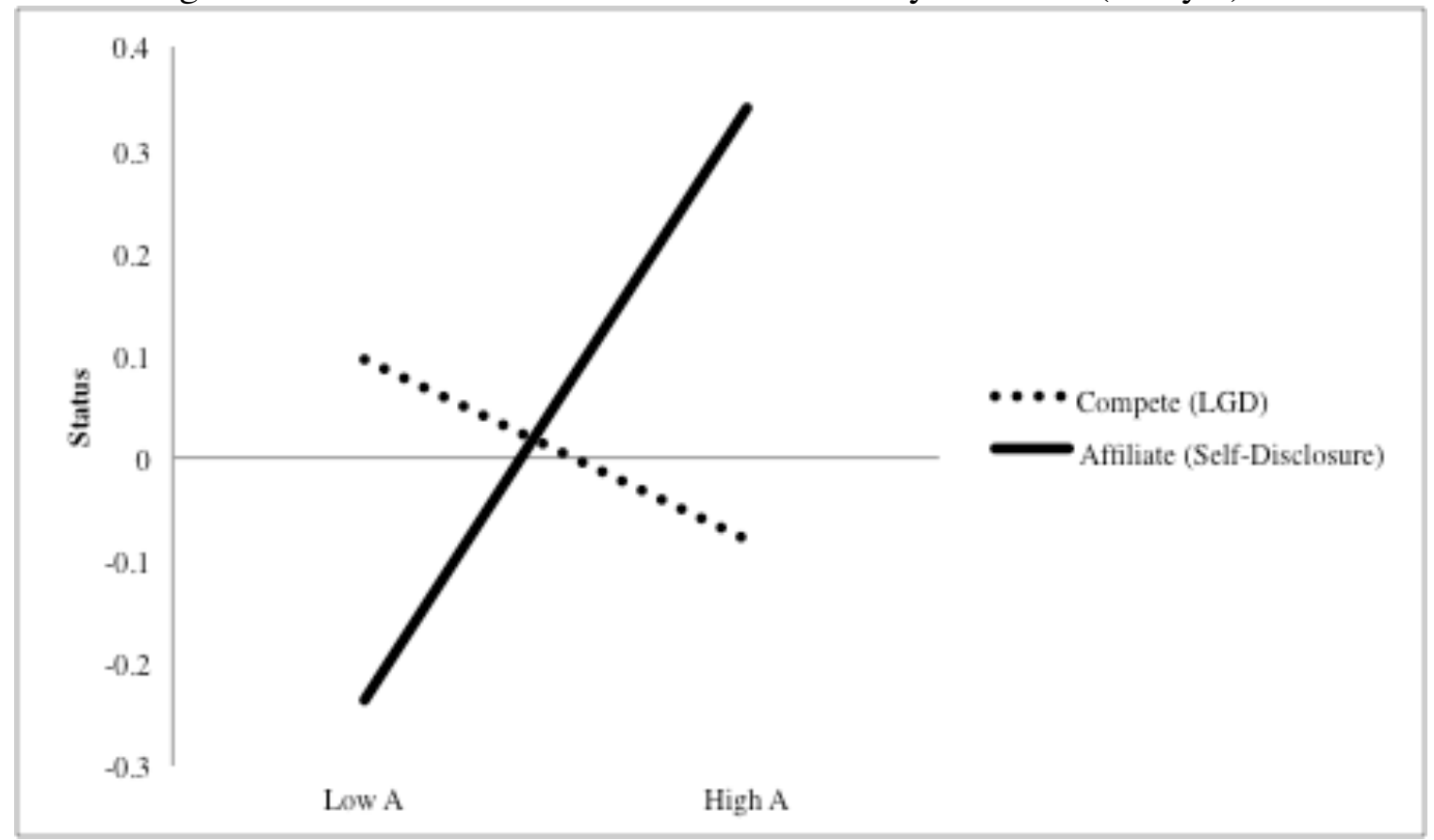

Fig. 2.

Effect of agreeableness on status attainment moderated by condition (Study 2)

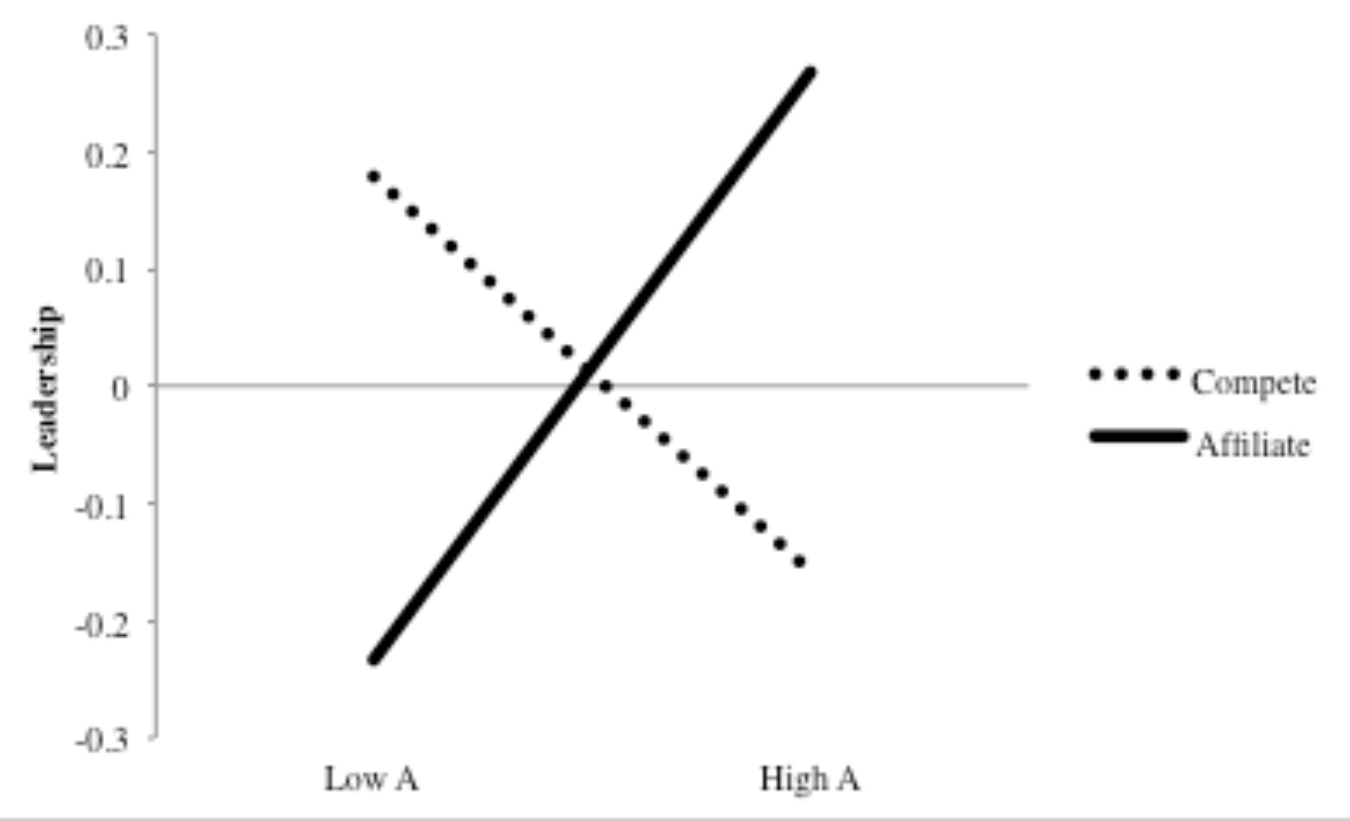


Fig. 3.

Mini Meta-Analysis Forest Plot

Source

r $[95 \% \mathrm{CI}]$

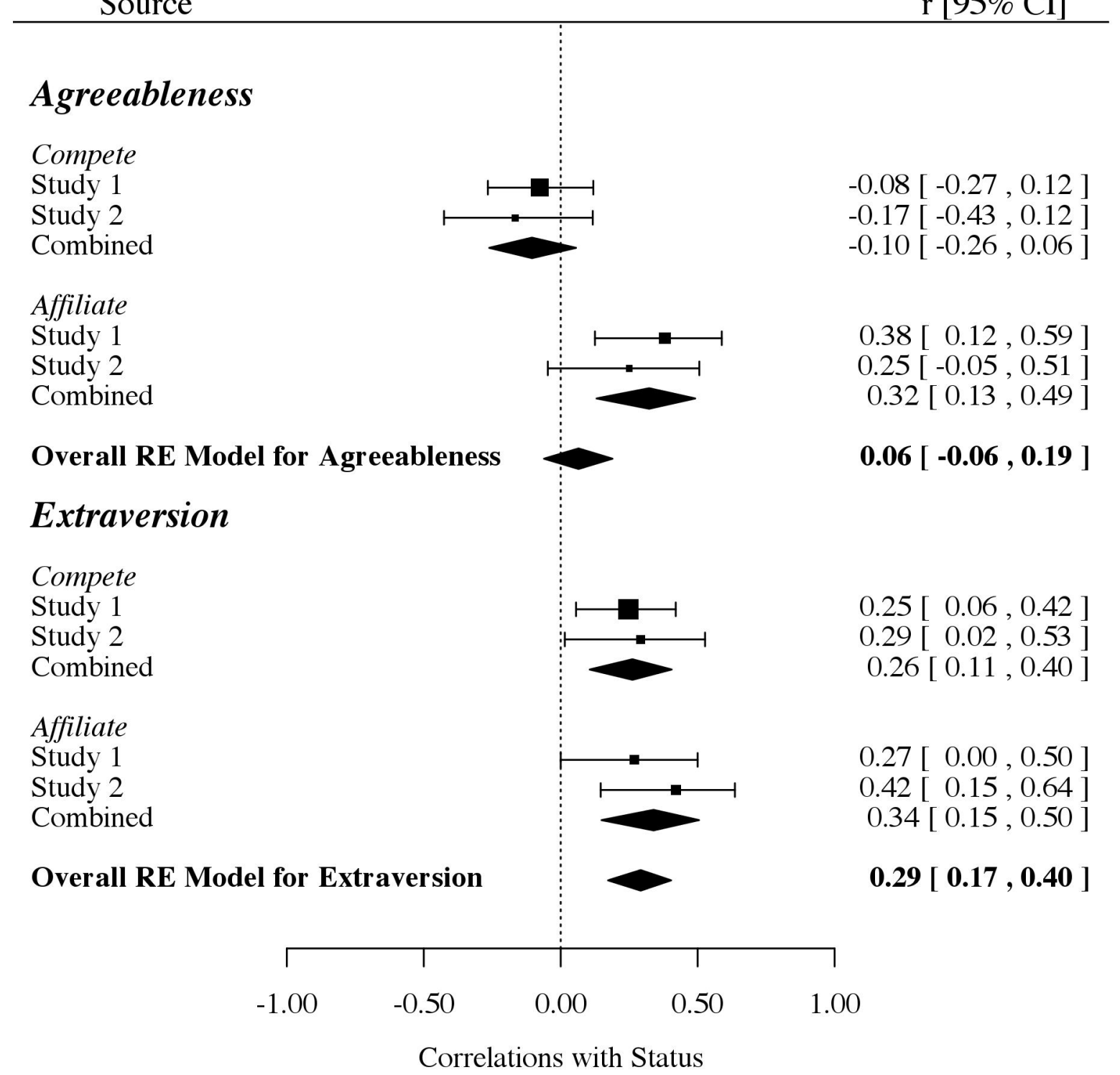




\section{STATUS ATTAINMENT ACROSS SOCIAL CONTEXTS}

\section{Supplemental Material}

\section{Analyses of Conscientiousness, Neuroticism, and Openness}

Although we did not have hypotheses about the association between the three remaining Big Five traits and status, we conducted analyses to explore these effects. Descriptive statistics and alpha coefficients can be found in Table S1. In Study 1, we found evidence that participants who were highly conscientious attained status regardless of the group task, but we found no clear relationship between neuroticism or openness and status. We did not find evidence that condition moderated the relationship between these traits and status (see Table S2). In Study 2, we found no evidence of associations between openness or conscientiousness and status, nor were these effects moderated by condition. However, the data suggested that individuals higher in neuroticism attained less status in both tasks in this study. Full results can be seen in Table S3. 
Table S1.

Pre-interaction descriptive statistics

\begin{tabular}{|c|c|c|c|c|c|c|c|}
\hline \multirow[b]{2}{*}{ Trait } & \multirow[b]{2}{*}{ Condition } & \multicolumn{3}{|c|}{ Study 1} & \multicolumn{3}{|c|}{ Study 2} \\
\hline & & $M$ & $S D$ & $\alpha$ & $M$ & $S D$ & $\alpha$ \\
\hline \multirow[t]{3}{*}{ Conscientiousness } & Compete & 3.69 & 0.67 & .83 & 4.77 & 0.98 & .57 \\
\hline & Affiliate & 3.64 & 0.64 & .81 & 5.12 & 1.11 & .69 \\
\hline & Total & 3.67 & 0.66 & .82 & 4.93 & 1.05 & .63 \\
\hline \multirow[t]{3}{*}{ Neuroticism } & Compete & 2.67 & 0.67 & .80 & 4.38 & 1.24 & .71 \\
\hline & Affiliate & 2.75 & 0.54 & .65 & 4.30 & 1.34 & .75 \\
\hline & Total & 2.70 & 0.63 & .76 & 4.34 & 1.28 & .73 \\
\hline \multirow[t]{3}{*}{ Openness } & Compete & 3.71 & 0.59 & .80 & 4.89 & 1.04 & .61 \\
\hline & Affiliate & 3.64 & 0.65 & .80 & 4.85 & 1.01 & .67 \\
\hline & Total & 3.69 & 0.61 & .80 & 4.87 & 1.02 & .63 \\
\hline
\end{tabular}

Note: Self-reports of personality in Study 1 were made on a 1 (disagree strongly) to 5 (agree strongly) scale; self-reports in Study 2 were made on a 1 (not at all true) to 7 (totally true) scale. 
Table S2.

\begin{tabular}{llllll} 
& & $\boldsymbol{b}$ & \multicolumn{1}{c}{$\boldsymbol{S E}$} & \multicolumn{2}{c}{$\mathbf{9 5 \%} \mathbf{C I}$ for b } \\
\hline Conscientiousness & Conscientiousness & 0.25 & 0.08 & 0.09 & 0.41 \\
& Condition & 0.01 & 0.08 & -0.15 & 0.17 \\
& C X Condition & -0.06 & 0.08 & -0.22 & 0.11 \\
& Neuroticism & -0.08 & 0.09 & -0.26 & 0.10 \\
& Condition & 0.01 & 0.09 & -0.16 & 0.17 \\
& N X Condition & -0.03 & 0.09 & -0.21 & 0.16 \\
\hline Openness & Openness & 0.14 & 0.08 & -0.02 & 0.30 \\
& Condition & 0.01 & 0.08 & -0.16 & 0.17 \\
& O X Condition & -0.05 & 0.08 & -0.21 & 0.11
\end{tabular}

Note: Personality traits and status are z-scored. Condition is coded as -1 = LGD and $1=$ self-disclosure.

Effects of Conscientiousness, Neuroticism and Openness on Status (Study 1)

Table S3.

Effects of Conscientiousness, Neuroticism, Openness, task and condition on leadership (Study 2)

\begin{tabular}{llllll} 
& & $\boldsymbol{b}$ & \multicolumn{2}{c}{$\boldsymbol{S E}$} & \multicolumn{2}{c}{$\mathbf{9 5 \%} \mathbf{C I}$ for $\boldsymbol{b}$} \\
\hline Conscientiousness & Conscientiousness & -0.14 & 0.11 & -0.35 & 0.07 \\
& Condition & 0.02 & 0.11 & -0.19 & 0.23
\end{tabular}


STATUS ATTAINMENT ACROSS SOCIAL CONTEXTS

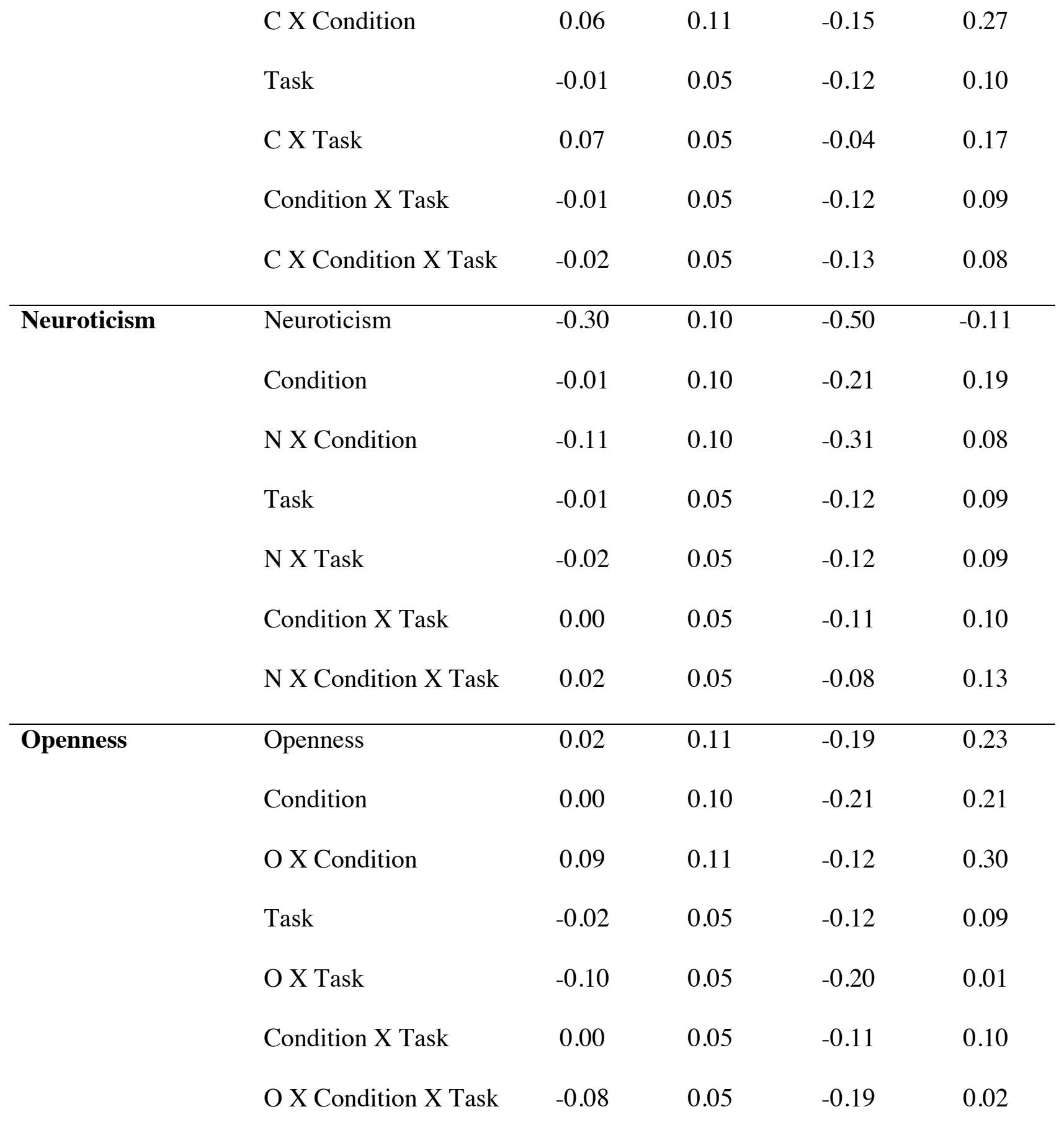

Note: Personality traits are z-scored. For analyses without task effects, leadership is the z-score of the average of the two leadership ratings. For analyses that include task effects, leadership is the difference between the two leadership ratings $z$-scored based on the pooled mean and standard deviation. Condition is coded as $-1=$ compete and $1=$ cooperate. 


\section{STATUS ATTAINMENT ACROSS SOCIAL CONTEXTS}

\section{Discussion}

Whereas the hypothesized effects of extraversion and agreeableness were stable across our studies, we found inconclusive evidence regarding the associations between the other Big Five personality traits and status. These traits may be less relevant to status. Alternatively, like agreeableness, these traits may only matter when they are relevant to the group's task - their relationships with status attainment might be moderated by contextual constraints that were not systematically manipulated or measured in this study. Recent work on person-environment fit"the compatibility between an individual and a work environment" (Kristof-Brown, Zimmerman \& Johnson, 2005, p. 281) - lends credence to this idea. In one study, peer-rated influence (a construct related to status) was associated with conscientiousness in an organization where detail-orientation was highly valued, but not in one that valued teamwork (Anderson, Spataro \& Flynn, 2008).

\section{References}

Anderson, C., Spataro, S.E. \& Flynn, F.J. (2008). Personality and organizational culture as determinants of influence. Journal of Applied Psychology, 93, 702-710. doi: 10.1037/0021-9010.93.3.702

Kristof-Brown, A. L., Zimmerman, R. D., \& Johnson, E. C. (2005). Consequences of individuals' fit at work: A meta-analysis of person-job, person-organization, persongroup, and person-supervisor fit. Personnel psychology, 58, 281-342. doi: 10.1111/j.17446570.2005.00672.x 
STATUS ATTAINMENT ACROSS SOCIAL CONTEXTS 